\title{
Importância da Filosofia na educação crítica: a utilidade da técnica no processo inclusivo de pessoas com necessidades especiais
}

\author{
Saulo Sebastião de Souza ${ }^{1}$ \\ sauluss@ig.com.br
}

\begin{abstract}
Resumo
Neste artigo discute-se tecnologia, Educação e Filosofia. Defende-se a importância da Filosofia na educação geral e na educação inclusiva. Discute-se a questão do "poder 'libertador' da técnica e da industrialização do capitalismo inglês na Índia", compreendido como "princípio civilizacional", resultado da "ciência/técnica moderna pósrevolução industrial", tese defendida por Marx, e algumas implicações atuais. São apresentadas, sucintamente, outras ideias filosófico-sociais, econômicas e ideológicas (Adorno, Horkheimer, Heidegger, Marcuse) ao modelo marxiano. Há também reflexões sobre a importância da tecnologia na Educação em geral e na deficiência visual - tradicional (escrita Braille, por exemplo) e atual (tecnologias digitais: letras ampliadas na tela do computador, softwares especializados para leitura e escrita). São analisados alguns prós e contras da tecnologia na perspectiva do objeto-problema dissertativo do autor sobre a inclusão educacional de deficientes visuais ${ }^{2}$. Adianta-se parte da pesquisa atual
\end{abstract}

1 Licenciado, bacharel e especialista em Filosofia e Didática do Curso Superior pela Universidade Federal de Minas Gerais (UFMG) e Faculdade São Luiz. Mestre em Educação pela Universidade do Estado do Rio de Janeiro (UERJ), docente da Faculdade de Educação da Universidade do Estado de Minas Gerais - FaE/CBH/UEMG.

2 Inclusão de alunos deficientes visuais na universidade: focalizando os professores e os funcionários, defendida na Universidade do Estado do Rio de Janeiro - UERJ (03/03/2009).

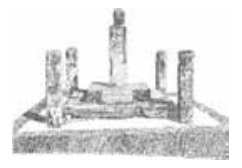


do autor sobre a Educação, que trabalha com a hipótese de que a escrita grega, iniciada por Homero, foi a mais importante "contribuiçãorevolução" para a humanidade. Analisa-se a importância da Educação/Pedagogia e o papel do ensino de Filosofia nos dias atuais, fundamental à formação da consciência crítica-cidadã, pressupostos, meio e fim.

Palavras-chave: técnica; inclusão; educação.

\section{Introdução}

Quem deixa a escola com gritos de alegria, seu nome será efêmero (MANACORDA, 2006, p. 23).

A Filosofia e a ciência, metodologicamente, encerram um caráter "tecnológico": eficientes instrumentos de indagação, capazes de "arrancar", "desvelar", transformar o "saber oculto na natureza", localizado no mundo da objetividade (natureza fenomênica) ou da subjetividade (cultura, símbolos e ideias). Há sentido emitir juízos de valor à Razão por mau emprego humano da técnica, porque em essentia (ousía) é um "neutro", benéfico ou maléfico? A intencionalidade sempre será elemento determinante da ação, positiva ou direta ou indiretamente na pesquisa.

$\mathrm{O}$ artigo parte da tese de que a escrita, no caso o alfabeto vocálico grego, foi a "primeira técnica cultural humana" geradora da maior revolução cultural da história ocidental, importante inclusive para a Filosofia, marco divisor da Idade da Pedra à civilização. Mas o Ratio não é dado inato, autônomo, acabado, definitivo, mas uma construção permanente (fenômeno simbólico, cultural, nato, heterônomo, "não genético"). Porém, vale registrar, a contribuição grega à nossa civilização somente foi possível a expensas da "educação-escola escrita grega" (grammatistés) (MANACORDA, 2006); esta é o princípio, meio e fim do artigo. A educação compreende: 
A palavra "educação" (do latim educare, no grego paidagogein) tem sentido humano e social. E um ato que se verifica desde as origens da sociedade humana. Caracterizase como um processo por obra do qual as gerações jovens vão adquirindo os usos e costumes, as práticas e hábitos, as idéias (sic) e crenças, numa palavra, a forma de vida das gerações adultas (LARROYO, 1974, p. 15).

Educação é a maior criação humana de transformação social, pedagógica e politicamente desenvolvida na sociedade burguesa, apropriada pelos trabalhadores (ARROYO, 2005; SOUZA, 2009), veículo utilizado pela inclusão educacional para a libertação dos processos de discriminação, exclusão, dominação e divisão de classes (Marx) de pessoas com necessidades especiais. Entretanto, somente com a consciência crítica é possível vencer a alienação, pois é "desta constatação que surge a interrogação da natureza do poder, da legitimidade e seu exercício e da origem da participação e da cidadania" (ARROYO, 2007, p. 61). Destacar o papel e a importância da Educação - geral e especial - e a relação desta com a Filosofia é a questão central do artigo.

Discutir pontos relevantes à técnica e à educação inclusiva é o objeto em questão. Neste contexto, entende-se a educação inclusiva como a superestrutura da educação geral: processo dinâmico, dialético, de natureza complexa, estruturada social, cultural, política e pedagogicamente, envolvendo instituições, poderes, ciências etc. Ela propiciou condições de ensino-aprendizagem a pessoas que apresentam limitações conjunturais, físicas, emocionais e psíquicas, proporcionando-lhes respeito pessoal, dignidade social, crescimento cultural e econômico. A inclusão educacional vem modificar séculos de injustiças culturais, sociais e políticas das elites contra as minorias exploradas, excluídas e discriminadas. Resgatar a dignidade desse alunado por meio do conhecimento escolar é seu nobre propósito (SOUZA, 2009). O ensino inclusivo é a "prática da inclusão de todos - independentemente de seu talento, deficiência, origem socioeconômica ou origem cultural -

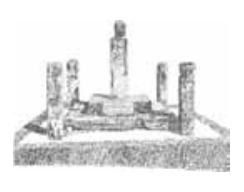


em escolas e salas de aula provedoras, onde todas as necessidades dos alunos são satisfeitas" (STAINBACK; STAINBACK, 1990, p. 22). Evidencia-se a importância social e política da escola como instituição que transcende à simples produção do saber teórico, da educação heroica homérico-aristocrática, cavalheiresca, monástica, burguesa (gentleman, John Locke) ou proletária.

No trabalho enfatiza-se a importância da Educação em todos os níveis, graus e modalidades. Defende-se também que a Pedagogia não é apenas a ciência da Educação por excelência, stricto sensu, como fala o professor Libâneo; ela deveria ser mais que isto, "a Ciência" reverenciada, respeitada e prestigiada por todas as instituições, culturas, povos e saberes. Infelizmente, outros interesses se interpõem à prática educativa, desviando-a do verdadeiro objetivo. Essa situação pode ser percebida na grande distância muitas vezes existente entre a escola e a realidade ${ }^{3}$ de professores e, principalmente, de alunos ${ }^{4}$. Esse fato se verifica na pragmática do "currículo oficial-verticalizado", comum a todo alunado, que favorece apenas a "clientela dominante", familiarizada com esse tipo de cultura, costumes, valores e saberes. Por não aprofundar na questão, omite, mascara ou oculta as diferenças culturais e sociais, pressupostos, objetivos e necessidades, principalmente a divisão social de classes. Essa prática surge com a educação liberal e iluminista (Locke, Rousseau, entre outros) e na escola tradicional, imposta como padrão ("norma culta") ao proletariado.

Mas não basta apenas "trabalhar a educação"; é preciso que ela seja de qualidade, gratuita e democrática, porém, que seja questionadora, associada, pois, à reflexão filosófica, voltada à criação de uma consciência cidadã, fugindo às formas acríticas de produção do saber, apropriadas à dominação. É preciso criar no alunado o hábito da interrogação, do questionamento, da dúvida,

3 Pelo latim, res, coisa, objeto, pelo grego phainómenon, sinônimo de realidade física phaenómenon. 4 Vale lembrar que o capitalismo é plural, complexo e diversificado e não simples e uniforme como a escola apresenta. Mas isto não fortuito ou inocente, pois faz parte do projeto político da burguesia, do liberalismo ao neoliberalismo, quando a nova ordem faz da educação escolar seu principal instrumento de transmissão do saber, mas, sobretudo, de controle, dominação e reprodução político-ideológica. 
enfim, estabelecer um "estado de krísis": capacidade de provocar o espanto (pathos) e a admiração (o thauma, platônico), fatores essenciais à condução da reflexão crítica (kritiké). Mas é "possível o ensino da Filosofia? Não. A Filosofia não é ensinável. O que se ensina e o que se pode aprender é a filosofar" (VELLOSO, 1968, p. 11). Filosofar é puro exercício de pensar, de "usar da "Razão, principalmente no que nos concirna e toque - em nossa peculiar e íntima essência" (VELLOSO, 1968, p. 14 - 15).

É demandar a verdade por via especulativa. É raciocinar, discutireargumentarcomoSócrates com os Sofistas, e pensar, refletir, aprofundar, generalizar, relacionar, concatenar idéias (sic), estruturar conhecimentos. [...] Todavia, [...] não basta estar a caminho, não basta estar em marcha, é preciso que estejamos no caminho exato. Eis porque o filosofar é também um método, pois método não significa outra coisa que o caminho a seguir. [...] Filosofar é conhecer as coisas como são - NA SUA REALIDADE ÍNTIMA - e não na sua realidade útil e corrente da vida quotidiana, pois a Filosofia [como o Filosofar] é PARA ULTRAPASSAR A CONDIÇÃO HUMANA (VELLOSO, 1968, p. 14-16).

É sempre oportuno relembrar, com Velloso, das palavras de Kant: "Não se ensina Filosofia, mas a filosofar" (PALACIOS, 2009 , p. 1). Infelizmente, algumas "escolas" de Filosofia, ao invés de ensinarem a filosofar, trabalham o acúmulo "bancário" de pensamentos e de sistemas filosóficos (erudição pura e simplesmente), alheias ou "inconscientes" à promoção da atitude crítica, à criatividade gnosiológica e epistemológica. Assim pensando, o "verdadeiro filósofo" é idêntico ao "verdadeiro educador", pois o sábio é aquele que, por saber, ensina, mas, sobretudo, vive seu saber. Mesmo porque, como disse o "pai da Filosofia" (fase humanista, antropológica), Sócrates, "uma vida sem busca (isto é, sem reflexão) não vale a pena ser vivida" (SÓCRATES apud REALE/ ANTISERI, 1990, p. 2).

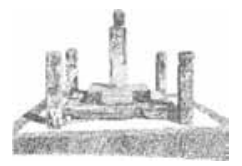


O filosofar tem de ser radicalmente isento e livre de quaisquer peias e entraves, venham êles (sic) do Estado ou da Religião, do status econômico ou político. Uma coisa é viver para a Filosofia como aproveitador da Filosofia. Uma coisa é viver para as mais sublimadas atividades do espírito, outra é viver mercenariàmente (sic) como sofista ou como filistino ${ }^{5}$ (VELLOSO, 1968, p. 9).

Nesses termos, fica evidente a missão da Filosofia na edificação do saber: ser reflexiva (filosofia) e empírica (ciência), método para "desvelar o ser" (Heidegger), tarefa na qual a Filosofia é insuperável e insubstituível, reflexiva por essência. Portanto, antes de gnosiológica ou epistemológica, a Filosofia é um processo de conhecimento pedagógico-educativo, porém crítico. Essa vocação é ampliada com Sócrates ${ }^{6}$ que, desde cedo, percebeu essa relação e a importância da Educação: conhecer as coisas à sua volta, mas, sobretudo, conhecer a si mesmo: "nosce te ipsum" ("Conheça-te a ti mesmo!"), principio moral-educativo.

Sócrates percebeu, com profundidade, que o fenômeno educativo era auto-atividade (sic). Mediante perguntas pertinentes (forma dialogada), o mestre levava os alunos a encontrarem, por si mesmos, o buscado. Tudo isto por um processo que partia da experiência concreta e singular para elevar-se às idéias (sic) gerais (método epagógico; de epagogé, indução) (LARROYO, 1974, p. 163).

Porém, a experiência tem demonstrado a ausência da academia na construção de uma sociedade crítica, livre e independente. Encastelada aos velhos pressupostos e objetos teóricos, às vezes sentimos a necessidade de maior presença da Filosofia na discussão de questões importantes da vida nacional - caso das novas tecnologias, da educação e da política. Mas não basta o esforço dos filósofos educacionais; é preciso também o apoio da Filosofia geral, do ensino básico, fundamental, médio e superior na construção de 6 Considerado "o pai da filosofia" (humanista, ético-moral, social, política). 
uma sociedade mais justa e verdadeiramente democrática, pois somente assim a Educação terá cumprido sua nobre função.

\title{
Tecnologia e industrialização inglesa: "princípio civilizador" ou ideológico
}

\author{
Os filósofos se limitaram a interpretar \\ o mundo de diversas maneiras; o que \\ importa é modificá-lo. \\ (Karl Marx)
}

A Razão ${ }^{7}$, mãe de todas as realizações humanas, sinônimo de "inteligência" ${ }^{8}$ imediatamente ao nascimento da Filosofia (Tales de Mileto, VI a.C.), produziu uma antinomia prático-metodológica ao se opor ao trabalho manual, porque, eivado de preconceito, tornou-se sinônimo de trabalho inferior (Platão), labor escravo (Aristóteles). Desse modo, a "arte (trabalho) intelectual", Filosofia por excelência, tornou-se, por séculos, exemplo de "trabalho superior". A técnica, tékne, in lacto sensu, significa trabalho, ofício, ação inteligente da humanidade (NUNES, 1991). Atividade voltada a um fim prático (práxis). A arte antiga transcendia ao conceito estético (póiesis) atual, ligado à ideia do Belo (to kalón, Aristóteles), era uma abstração pura, um "deleite estético".

Ars, artis, palavra latina que derivou, corresponde ao grego tékne, que significa todo e qualquer meio apto a obtenção de determinado fim, e que é o que se contém na idéia (sic) genérica de arte. Quanto à póiesis, de significado semelhante à tékne, aplica-a Aristóteles, de modo especial, para designar a poesia e também a Arte, na acepção estrita do termo (NUNES, 1991, p. 17).

Mas o preconceito se serve também da tecnologia. Caso curioso é o de Marx, ardoroso admirador da tecnologia, que

7 Do grego Logos, pelo latim Ratio/Ratione: raciocínio, inteligência, operação racional rigorosa, raciocínio palavra.

8 Pelo latim intelligentia, "intos legere", "ver/ler dentro". A filosofia inteligência, tanto no seu primeiro período, pré-socrático, socrático e pós-socrático, entendia a filosofia como a pura expressão da ratio/logos, logo, inteligência.

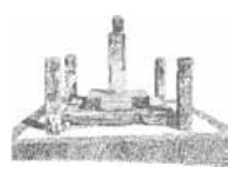


se fez porta-voz do moderno preconceito científico-burguês ao afirmar que certas civilizações seriam inferiores, "marginais à cultura 'superior' burguesa ocidental", a exemplo da Índia. Marx acreditava no "poder civilizador da industrialização" para a mudança estrutural da vida humana, principalmente das nações não industrializadas, ideia comum em seu tempo; função essa delegada à ciência e à técnica por meio do capitalismo industrial:

a discussão possui como ponto de partida dois artigos de Karl Marx: 'O domínio britânico na Índia' e 'Futuros resultados do domínio britânico na Índia'. Ambos contêm a ideia da técnica moderna como princípio civilizador: o papel da nação capitalista mais avançada do século XIX seria o de 'civilizar' a 'tradicional' sociedade indiana mediante a inserção da estrutura produtiva industrial, onde o aparato técnico-científico possui destaque (GALLO, 2005, p. 25).

O entendimento de Marx perdurou até o apogeu do capitalismo (século XX). Heidegger, Adorno, Horkheimer e Marcuse, por exemplo, entendiam a técnica como meio, ação, instrumento (órganon, organu, em grego e latim, ferramenta) por excelência de intervenção e exploração da natureza. Porém, sem separá-la das relações de poder e sem a ideologia de neutralidade científica alheia aos interesses sociais ou políticos e econômicos de dominação, divisão e exploração de classes. Para Marx, a técnica funcionava como uma espécie de "força-motriz", energia capaz de mudar os rumos das "civilizações primitivas" por intermédio da industrialização. Desse modo, a presença política do capital inglês na Índia era, para Marx, indispensável para trazer à sua colônia a modernidade ocidental.

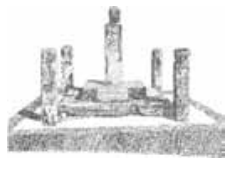

92

Os ingleses foram os primeiros conquistadores de civilização superior à hindu e, por isso, ficaram imunes à ação desta última. Os britânicos destruíram a civilização hindu quando dissolveram as comunidades nativas, arruinaram por completo a indústria indígena e nivelaram tudo que era grande e elevado da sociedade nativa. A indústria

Ano 13 - n. 16 - dezembro 2010 - p. 85-113 
moderna [...] destruirá a divisão hereditária do trabalho, base das castas hindus, esse principal obstáculo ao progresso e ao poderio da Índia (MARX apud GALLO, 2005, p. 31).

Ideologicamente, o princípio civilizador justificava-se pela "imanência lógica (natural) inerente ao sistema", que conferia individualidade, autonomia e independência à técnica. Ou seja, a técnica não era uma criação da natureza, mas uma invenção humana. Numa comparação cibernética, funcionaria como uma espécie de androide que, apesar de criação humana, tinha vida, ação e vontade próprias. O desenvolvimento científico e tecnológico, no entanto, acabou se alterando no avançar do tempo, "mas não devido a causas diretas de tal desdobramento, pela aplicação e utilização de seus recursos" (GALLO, 2005), ou seja, muito mais pela interferência de mecanismos ou agentes humanos, sociais, econômicos, políticos.

Adorno (1985), Horkheimer (1985) e Marcuse (1999) reconhecem a força impulsora da técnica moderna para o desenvolvimento e progresso humano. Recusam, entretanto, a tese marxiana do "princípio civilizador" e da "racionalidade tecnológica" (que conferia à técnica ação e vontade própria, herança da "racionalidade iluminista"), bem como o da "nova dinâmica" e a ideia do funcionamento eficiente do aparato. A contestação se justifica porque a técnica é uma criação (cultural) do homem, indissociável do sistema capitalista de produção. A visão marxiana de libertação do povo indiano pela aparelhagem técnico-industrial pode soar mítica, mesmo romântica, na contramão da crítica hodierna, a exemplo do aparelho ideológico do Estado (Althusser); os dispositivos de controle social efetuados pelo Estado capitalista mostraram-se equivocados porque a colonização inglesa na Índia não se revelou revolucionária, tampouco alterou o modo de produção, apesar de ter promovido o desenvolvimento econômico, industrial e principalmente científico-tecnológico da Índia. Ou seja, o tempo e a própria "lógica capitalista" (não a da técnica) encarregaram de desmentir esse e outros mitos inerentes ao modo de produção

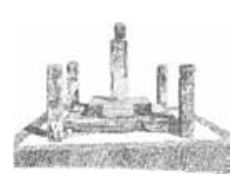


capitalista. De qualquer forma, Marx foi claro ao dizer que, para que a técnica, industrialização e capital inglês desse certo na Índia, era indispensável também que o proletariado industrial britânico não desalojasse do poder os governantes na Grã-Bretanha:

Os hindus não poderão colher os frutos dos novos elementos da sociedade, que semeou entre eles a burguesia britânica, enquanto na própria Grã-Bretanha as atuais classes governantes não forem desalojadas pelo proletariado industrial, ou enquanto os próprios hindus não forem fortes para acabar de uma vez para sempre com o jugo britânico (MARX apud GALLO, 2005, p. 27).

Todavia, se Marx foi utópico, Platão e muitos outros também o foram. Marx não viveu o suficiente para ver os resultados da dominação inglesa na Índia, Egito, China e África. Isso porque a técnica produziu o progresso e a riqueza, mas também ajudou na alienação, exploração e divisão de classes. Em outros termos, ao invés de libertar, contribuiu ainda mais para a alienação, como hoje se acredita que o domínio das tecnologias leva o indivíduo ao sucesso social, econômico, prestígio e poder, poder. Esse é um dos mais festejados mitos da pós-contemporaneidade. Resumindo, era cedo para que Marx desse conta de que o capitalismo inglês na Índia acabaria transformando tudo em "maquinaria" a serviço dos interesses da nova classe e modelo econômico dominante tão logo se tornasse hegemônico. Ponderando com Marcuse:

Não estamos tratando da influência ou do efeito da tecnologia sobre os indivíduos, pois são em si uma parte integral e um fator da tecnologia, não apenas como indivíduos que inventam ou mantêm a maquinaria, mas também como grupos sociais que direcionam sua aplicação e utilização (MARCUSE, 1999, p. 73).

Vivia-se uma idílica utopia positivista ultramoderna do "encantado" papel da ciência e da tecnologia. Por um lado, cabe considerar que a tecnologia produziu o "des-ocultamento", o "revelamento" do ser (Heidegger), contudo não produziu dividendos morais capazes de libertar o ser humano; ao contrário, ampliou 
ainda mais o processo de exclusão. Tornou-se, pois, necessário pensar a questão da "essência da técnica" (Heidegger) em busca do "caráter técnico-industrial do relacionamento homem/sociedade e o ambiente natural", dentro do conceito frankfurtiano da kulturkrit (GALLO, 2005, p. 32-34). Segundo Adorno/Horkheimer, essa associação "mítica" "implica uma falta de autoconsciência do que viria a ser o esclarecimento desmistificador, acabando por culminar naquilo que o pensamento, a razão vêm a combater: o mito" (ADORNO; HORKHEIMER, 2005, p. 7).

Se a produção técnico-industrial tem de ser vista com reservas (ideológicas), não quer dizer que o aparato científico moderno (eletrônica, computador, metalurgia e petroquímica, por exemplo) tenha que ser menosprezado, posto tratar-se de valiosos instrumentos inclusivos do resgate da dignidade e cidadania, negadas principalmente às pessoas com necessidades especiais (SASSAKI, 2006). Vale lembrar que os deficientes físicos, auditivos, visuais e mentais, bem como as pessoas que lidam com esse público, destacadamente os professores, são igualmente beneficiados por tais tecnologias.

Os deficientes mentais, por exemplo, sem o auxílio das novas tecnologias, estariam fadados, senão à marginalidade, ao menos à exclusão cultural e educacional. Vale lembrar que, nesse caso, não nos referimos apenas às tecnologias da computação, mas a todo o aparato científico, caso dos sistemas de linguagemcomunicação específicos para os deficientes mentais, da língua de sinais (libras) para os surdos, do Braille e do alto relevo para os cegos. A utilização dessas tecnologias teve início em 1784 com a criação, por Valentin Haiiy, do Institute Nationale des Jeunes Aveugles de Paris, a primeira escola (pública) para cegos registrada no Ocidente. Vale reforçar, porém, que a inauguração dessa escola especial será o berço da futura inclusão educacional, como pode se observar nos registros históricos.

Charles Barbier (oficial francês) cria a primeira escrita para cegos. Louis Braille (1829) cria o atual sistema de escrita Braille, mundialmente

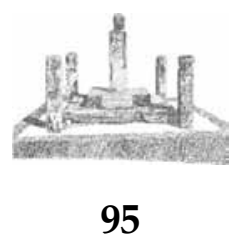


utilizado na alfabetização e escrita para cegos, fazendo uma revolução na educação para os deficientes visuais (MAZZOTTA, 2006 apud SOUZA, 2009, p. 18, 19, 100).

\section{A tecnologia na educação geral e educação inclusiva de deficientes visuais}

Se me demoro a falar e peço algum tempo, tu não deves ficar surpreso, nobre rei; a um ser privado da vista, uma grande parte da verdade fica escondida. Entretanto, eu irei lá aonde me chamam a pátria e a vontade de Febo; do Destino arranquemos os segredos.

(Tirésias. In: SÊNECA, 1982, p. 49)

Como já frisamos, o crucial problema não é com a técnica em si, mas como ela é apropriada e aplicada na sociedade contemporânea, pois, no caso dos deficientes, o emprego da tecnologia pode fazer toda a diferença. Os deficientes mentais, por exemplo, sem o auxílio das novas tecnologias, estariam fadados à exclusão cultural e educacional.

São históricos e universais os problemas vividos pelos deficientes, da antiguidade à contemporaneidade, passando pelos modelos da exclusão, médico, normalização, integração e inclusão, sendo a omissão e a ausência do Estado uma constância ad seculum (FOUCAULT, 2005). Em Esparta, as crianças deficientes eram atiradas do alto do monte Taigeto. Em Roma, o pátrio poder (Lei das XII Tábuas) dava direitos ao pai de eliminar "filhos defeituosos", considerados "seres subumanos". Mas além dos deficientes, pessoas com doenças crônicas, contagiosas, caso da epilepsia, lepra, tuberculose e loucura também sofriam as mesmas práticas e estigmas, registros, aliás, comuns na história dos povos e culturas humanas, como em Esparta, onde as

crianças portadoras de deficiências física ou 
legitimava sua eliminação ou abandono. [...] Porém, o fato mais marcante na sociedade grega em relação às pessoas com deficiências foi a prática da eliminação. Desde o arremesso até a exposição proposital há uma situação de abandono que conduzia, na grande maioria das vezes, à morte. [...] na Republica de Platão [...] apenas os bem formados de corpo e de espírito teriam qualquer papel. A criança ou o adulto deficiente estaria, nessa hipotética realidade, fadado a morrer (BOTURA; MANZOLI, 2003, p. 24).

Na Idade Média, com o Cristianismo, a condição dos deficientes sofre algumas mudanças significativas, ao serem percebidos como "criaturas de Deus", dignas de piedade e cuidado. Ao "ganhar alma", não poderiam ser eliminados ou abandonados do convívio social" (BOTURA; MANZOLI, 2003, p. 24), embora alguns direitos, como a educação, fossem ainda impensáveis. $\mathrm{O}$ direito à educação viria somente a partir do final do século XVIII, com as escolas especiais e a criação de métodos e técnicas apropriadas no processo de ensino e aprendizagem. É nesse contexto que surge, revolucionariamente, o alfabeto Braille como o primeiro instrumento inclusivo a alterar profundamente a vida de cegos e deficientes visuais, abrindo-lhes também inéditas perspectivas à cultura, à educação e à escola, até então impraticáveis. Esses métodos se estenderam também para outros deficientes (surdosmudos, por exemplo).

Valentin Haiiy [1784, fundador do destacado "Instituto Nacional para cegos de Paris", marco da educação especial, "precursor da inclusão"]. [...] Há também Charles Barbier [1819, nome singular na educação especial]. Outro importante nome para ser designado como "precursor" do ensino inclusivo voltado aos deficientes visuais, Louis Braille, que revolucionou toda a história da educação para cegos e deficientes visuais [1824], Jean Marc Itard [1838], Jean Seguin, etc. (MAZZOTTA, 2006 apud SOUZA, 2009, p. 47).

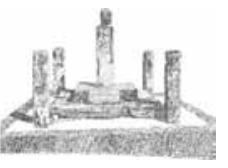


O primeiro instrumento significativo contra a exclusão dos deficientes nasce com as escolas especiais, inaugurando, desse modo, o paradigma da compreensão científica - física, psicológica, social e pedagógica - da deficiência. Porém, se evade "das mãos dos padres", cai sob o "domínio médico de classificação" (COLL, 1995; SASSAKI, 2006; SOUZA, 2009). Nesse modelo, o objeto (doença ou lesão) predomina sobre o sujeito e todo o contexto. Por extensão, a capacidade de aprendizagem dos deficientes era diretamente proporcional à extensão do quadro patológico apresentado, no qual a lesão tinha caráter irreversível. Nesse paradigma, existiam apenas dois padrões pedagógicos para o ensino-aprendizagem, reforçados pela ciência, escola, professor, ensino público e privado, política etc., o da normalidade e o da anormalidade (BLANCA; GLAT, 2007).

Por muito tempo acreditou-se que havia um processo de ensino-aprendizagem "normal" e "saudável" para todos, válido indistintamente a todos os estudantes, tanto para os ditos "normais" bem como para aqueles que apresentavam algum tipo de dificuldade, distúrbio ou deficiência. Essa visão dicotômica reforça o mito de que existem dois grupos qualitativamente distintos de alunos: os "normais" e os "anormais" (isto é, "fora da norma", regra, lei, padrão) e, consequentemente, duas categorias distintas de professores.

Para o autor de "Eros e Civilização", há também a possibilidade de transformação da caracterização da técnica como aparato, ou seja, do questionamento da racionalidade tecnológica (MARCUSE, 1999) e a liberdade de expressão, a aprendizagem. A "medida nosológica" discriminava, estigmatizava e rotulava os alunos deficientes pelo diagnóstico, tipificados como "retardados", "idiotas", "débeis mentais".

O modelo filosófico-pedagógico da escola tradicional, em que a criança era modelada e transformada no "ideal adulto" (herança retrógrada do pensamento pedagógico de John Locke, século XVII), era outro empecilho inclusivo. Os deficientes mentais, por exemplo, pela natural dispersão de atenção, tinham muitas 
dificuldades de se adaptarem às rigorosas formas de ensino e disciplina, imposta "sob pena de punição e/ou reprovação" (BLANCA; GLAT, 2007, p. 17).

Os paradigmas da educação inclusiva somente começaram a superar o modelo especial a partir de 70. O sistema de ensinoaprendizagem das escolas especiais, que trabalhavam com a divisão do alunado em normais e anormais, e a aplicação dos testes de inteligência ("QI"), mesmo com dificuldades na ressocialização, decretou o fim de séculos de isolamento, perseguição, abandono e assim por diante, até então impostos aos deficientes. A escola especial teve, e ainda tem, importante função na educação; extinguila, substituindo-a pelo ensino inclusivo, mesmo com todas as condições, é inaceitável, principalmente à economia de verbas, como parece querer o MEC e algumas Secretarias Estaduais de Educação.

Pelos motivos expostos e outros tantos ligados à situação socioeducativa dos deficientes, antes e depois da escola especial, não é difícil entender por que o modelo inclusivo vem revolucionando todos os processos anteriores ligados às pessoas com deficiências no campo do entendimento, ação e intervenção educativo-escolar. A diferença básica da educação inclusiva com os regimes anteriores é que os alunos se encontram dentro de uma escola e sala de aula regular, junto a alunos sem deficiência, branda ou rebelde, ao contrário do ensino especial que impedia esse contato. Trabalhos inclusivos demonstram a importância da convivência mútua, pois a experiência humana estimula o sujeito, reforça a aprendizagem e influencia positivamente no quadro orgânico da deficiência (GLAT, 2007).

Dada a oportunidade, alunos de todas as idades e de capacidades diversas demonstram serem capazes de atuar como colaboradores no planejamento e participarem do funcionamento de classes e escolas para todos. Os alunos cuja presença tem sido impensável nas salas de aula regulares, devido às suas óbvias incapacidades, podem contribuir

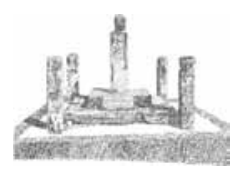


mais do que qualquer outro para construir uma comunidade de aprendizagem ativa. Trabalhando juntos, alunos, professores e pais podem criar comunidades escolares que contribuam mais para a educação de todos, exatamente porque se envolvem abertamente em problemas relacionados às dificuldades humanas e em incertezas que são facilmente mascaradas pela rotina (STAINBACK, STAINBACK, 1999, p. 61).

A importância da técnica/tecnologia no ensino inclusivo, à parte as questões ideológicas, é fundamental para todos os tipos de deficiência, a exemplo dos deficientes visuais, objeto da pesquisa dissertativa do autor. Os principais instrumentos fornecidos pelas novas tecnologias utilizadas na educação inclusiva se localizam no campo da informática: o sistema DOSVOX, Virtual Vision, o JAW, o scanner, máquinas de escrever e impressoras adaptadas para a impressão da escrita Braile (Máquina Perkins), lentes de aumento e instrumentos ópticos especiais adaptados ao trabalho do deficiente visual (BLANCO, 2007, p. 126, 127) vieram para ficar. As pranchas em alto relevo, bibliotecas com cabine sonorizada para os cegos, livros em Braille etc. Mas a educação inclusiva não deve voltar-se apenas à produção do saber e do domínio das tecnologias. Deve ousar mais, "libertar o espírito dos deficientes", trabalho que a Filosofia tem muito a contribuir com a educação, como vimos insistindo.

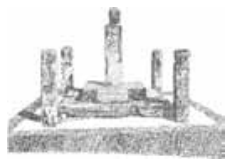

Aeducaçãodopovocomum, dos trabalhadores, na visão dos teóricos da economia política, é defendida apenas como mecanismo de libertação dos obstáculos que se podem opor a essa marcha inexorável do progresso econômico. Alguns desses obstáculos estavam nos preconceitos e na ignorância dos trabalhadores e, sobretudo, nas desordens sociais e políticas dos vencidos pela revolução burguesa: os camponeses, artesãos, pequenos proprietários e radicais, que tentavam desviar o curso da revolução desencaminhando as massas ignorantes (ARROYO, 2007, p. 54).

Ano 13 - n. 16 - dezembro 2010 - p. 85-113 
A pesquisa dissertativa citada demonstrou que a tecnologia na inclusão dos deficientes visuais no local pesquisado era fundamental, enquanto sua ausência dificultava, comprometia, mas não impedia a aprendizagem. Os notebooks, salvo o de uma aluna do turno da manhã, não faziam parte do trabalho dos deficientes visuais em sala de aula, ao contrário dos métodos tradicionais. A gravação - via gravadores, MP3/4 e outros - era a principal tecnologia utilizada. A produção de textos por meio de scanner, leitura, escrita e "edição digital", ferramentas inclusivas predominantes, dentro e fora da Universidade ${ }^{9}$, mostraram-se tão importantes quanto fora o alfabeto de Louis Braile, que abriu novas perspectivas à inclusão social dos cegos, por intermédio da educação.

\section{Intransferíveis reflexões críticas à Educação, ciência e tecnologias}

As virtudes (virctudes) têm sua origem nos romanos, a Cultura nos gregos.

(MANACORDA, 2006, p. 75)

Mas a quem servem as novas tecnologias? Essa é uma problematização que nunca deveria faltar na escola e sempre deveria ser levantada, incentivando, por exemplo, o diálogo franco, transparente e aberto entre o aluno, o professor, a instituição e a comunidade escolar, função do método filosófico por intermédio da reflexão crítica. Primitivamente, todos dependiam de todos. Com o trabalho coletivo, tudo era socializado e voltado à comunidade (BRANDÃO, 2005), sendo a terra o bem mais precioso. Historicamente, os processos de dominação iniciamse com a produção de excedentes. Nasce, assim, a divisão e a luta de classes, a separação da humanidade em detentores e não detentores de riqueza, do poder de uma minoria "rica" sobre uma maioria "pobre", superior, inferior e assim por diante. No 
capitalismo, a riqueza atinge cifras exorbitantes, à margem da socialização dos recursos amplamente produzidos; nele, uma minoria detém praticamente todos os bens, básicos ou não. Os bens culturais, outrora coletivizados, transformam-se, nas sociedades organizadas, em privilégios do clã ou da tribo, mas do grupo dominante, principalmente a educação.

É a partir daí que a educação aparece como propriedade, como sistema e como escola. O controle sobre o saber se faz em boa medida através do controle sobre o que se ensina e a quem se ensina, de modo que, através da educação "oficial", o saber oficialmente transforma-se em instrumento político de poder. Ele abandona a communitas de que fez parte um dia e ingressa na estrutura dos aparatos de controle. O "processo grego" se repete então: a educação da comunidade, a escola, a oposição entre a educação-de-educar e a educação de instruir, a passagem da aprendizagem coletiva para o ensino particular, o controle do estado. [...] onde surgem interesses desiguais e, depois, antagônicos, o processo educativo, que era unitário, torna-se partido, depois imposto. Há educações desiguais para classes desiguais (BRANDÃO, 2004, p. 102, 103).

É nesse sentido que se fala que o fim do processo inclusivo é dos mais nobres e importantes, pois objetiva corrigir parte dessas históricas distorções, porém, não deve restringir-se aos deficientes, pois não são eles os únicos historicamente excluídos, do ponto de vista social, político, cultural, econômico ou educacional. A inclusão visa a um mundo menos competitivo, exclusivista, individualista, cooperativo, que respeita as diferenças, interativo e que compartilha experiências, mas sem esquecer de omiti-las. Por isso, entendemos a inclusão escolar como um movimento universal de incluir todas as minorias, especiais ou não, à educação.

O objetivo da inclusão não é o de esquecer as diferenças individuais entre elas. [...] a 
inclusão nas escolas é criar um mundo em que todas as pessoas se reconheçam e se apoiem mutualmente, e esse objetivo não é atingido por nenhuma falsa imagem da homogeneidade e em nome da inclusão. Ao contrário, precisamos observar cuidadosamente a maneira como as escolas têm caracteristicamente se organizado em torno das diferenças individuais e como desenvolveram alternativas. [...] Entretanto, a alternativa não é inserir os alunos em grupos heterogêneos e ignorar suas diferenças individuais. [...] Precisamos encontrar maneiras de desenvolver comunidades escolares inclusivas que reconheçam as diferenças entre os alunos e suas necessidades, e isto dentro de um contexto comum (STAINBACK; STAINBACK, 1995, p. 407,408$)$.

Assim como a educação e outras criações humanas, a técnica e a tecnologia evidentemente não ficariam imunes aos interesses dos detentores de riqueza, títulos nobiliárquicos, poder político ou religioso e assim por diante. Nesse momento é que se torna imprescindível a educação crítica à libertação pessoal e política, como preconizava Freire. Esse é o espaço privilegiado da Filosofia, razão pela qual sua presença em todos os níveis, currículos e graus, particularmente nesses conturbados dias, deveria ser mais que necessidade, mas uma inadiável prioridade.

A escrita (grafe) configurou-se como a primeira "ferramentatecnologia" responsável pela produção, armazenamento e transmissão do saber elaborado, mas trouxe também consigo o poder, caso dos escribas no velho Egito. Na Grécia, a escrita sofre algumas inovações. Ao contrário de outros povos, Mesopotâmia, por exemplo, desce do pedestal da sacralidade (hieróglifo - escrita sagrada - egípcia), adquirindo contornos laicos e caráter universal, tendo como grande mentor Homero, "pai da cultura ocidental", com a Ilíada e a Odisséia, continuado por Hesíodo, com a Cosmogonia e Genealogia dos deuses. A Filosofia, esplendor da

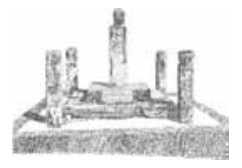


criação helênica, somente se tornou viável por obra do modelo grego de educação, porque, sem o peso do misticismo, aplanou o caminho para o surgimento do Lógos no lugar do Mython. São destacadas várias causas para o surgimento da Filosofia, porém, pouco destaque se faz à educação ${ }^{10}$, e isto, se não é um equívoco, com certeza é uma grande injustiça.

O resultado da técnica, essencialmente, não deve ser atribuído necessariamente ao instrumento ou à ciência, mas, principalmente, ao caráter político-social e ideológico oportunizado. Na verdade, o uso benéfico ou maléfico de uma ferramenta (órganon) é sempre uma escolha moral. A mesma ciência da bomba atômica de Hiroshima e Nagasaki serviu também à causa do bem, no tratamento do câncer. A manipulação tecnológica do césio, cobalto, urânio e de qualquer outro elemento radiativo, natural ou sintético, tem implicações negativas ou positivas - como o fim bélico de destruição em massa ou na "bomba de cobalto/césio" para o tratamento do câncer. A utilização da técnica pode ser puramente instrumental, imanente ou transcendente ao processo, mas não o seu fim, sujeito sempre a uma escolha, fato "não natural", um projeto humano intencional (Sartre).

No capitalismo globalizado eneoliberal, énormal eingênuo pensar que o uso de agrotóxicos e transgênicos na lavoura, anabolizantes na criação de gado ou frango são atividades "inocentes", seguras, economicamente sustentáveis, comprometidas eticamente e voltadas para os interesses da coletividade. Criar porcos é uma atividade científica segura, controlada cientificamente e fiscalizada pelo poder público? Esta é uma concepção mítica e de senso comum (doxa).

$\mathrm{Na}$ "gripe suína" temos um bom exemplo de como a técnica e a ciência podem ser manipuladas e controladas pelo interesse econômico.

O vírus dessa gripe se originou da combinação de múltiplos pedaços de ADN

10 Esta é conclusão parcial das pesquisas do autor a respeito da educação ocidental, que não poderia ter outra origem senão a educação helênico-helenística. No trabalho aponta-se uma estreita relação entre Educação e Pedagogia e entre esta com a Filosofia. 
humanos, aviários e suínos. O resultado é um vírus oportunista que acomete animais imuno-deprimidos, preferencialmente porcos criados comercialmente em situações inadequadas, não-naturais, intensivas, massivas, fruto de cruzamentos clonados e que se alimentam de rações de origem transgênica, vítimas de cargas extraordinárias de antibióticos, drogas do crescimento e bombas químicas visando a precocidade e o anabolismo animal. Especulações científicas indicam que o vírus dessa gripe teve origem nas Granjas Carroll, no Estado mexicano de Vera Cruz. A granja de suínos pertence ao poderoso grupo norte-americano Smithfield Foods, cuja sede mundial fica no Estado de Virgínia (EUA). [...] O nome da gripe, portanto, não é "suína". O nome da gripe é: "gripe do agronegócio internacional" - que precisa responder judicialmente o quanto antes - urgentemente - pela sua ganância e irresponsabilidade com a saúde pública mundial (PAITÁN, 2008).

Seja qual for a "verdadeira história da gripe suína"11 ,é impossível deixar a Smithfield Foods fora de suspeição. Fica afastada a "neutralidade científica" e "da técnica", porque não estão separadas das relações humanas de produção, principalmente por se tratar de uma empresa capitalista com fins lucrativos, mesmo porque o "homem não possui o controle sobre tal mecanismo: por isso a mitificação, alienação por meio da técnica moderna" (GALLO, 2005, p. 33). É nesse momento que entra a Filosofia como instrumento de "desocultamento" (HEIDEGGER) para denunciar a presença da alienação e da ideologia nesse tipo de trabalho/construção.

Parafraseando Adorno e Horkheimer (1985), como o homem não detém o "controle do mecanismo", sobrevém a mitificação e a alienação da técnica moderna. De acordo com eles, podemos concluir que não há nada desinteressado, ingênuo ou inocente na

11 Infecção viral do tipo gripal provocada por vírus mutantes de porcos e humanos. 
economia, na política ou na educação do capitalismo hodierno, no qual o processo é uma máquina e o homem, engrenagem dessa maquinaria.

O pensar reifica-se num processo automático e autônomo, emulando a máquina que ele próprio produz para que ela finalmente possa substituí-lo. [...] O procedimento matemático tornou-se, por assim dizer, o ritual do pensamento. Apesar da autolimitação axiomática, ele se instaura como necessário e objetivo: ele transforma o pensamento em coisa, em instrumento, como ele próprio o denomina (ADORNO; HORKHEIMER, 1985 apud GALLO, 2005, p. 28).

\section{Conclusão}

São obstáculos para a aprendizagem o medo e qualquer perturbação do espírito; enquanto o prazer facilita muito.

(MANACORDA, 2006, p. 77).

Vale colocar, ainda, uma última provocação. Se a Educação é responsável pela transmissão da cultura elaborada, a ciência, pela descoberta de novas realidades e a Filosofia, responsável pela organização (Comte), reflexão, lógica, metodológica e crítica, dos diversos saberes e realidades, reais e ideais, qual seria, então, a "utilidade" da técnica e da tecnologia? Para continuar a desafiar o homem a explorar as "energias da natureza para que realize o desocultamento do que está disposto" (GALLO, 2005, p. 2), ou seja, são ferramentas de exploração da realidade, no sentido de produzir os devidos conhecimentos ${ }^{12}$ e domínio sobre a natureza (Heidegger).

Quando, portanto, nas pesquisas e investigações, o homem corre atrás da natureza, considerando-a um setor

12 Segundo a teoria do conhecimento, o conhecimento nada mais é do que uma representação simbólica da realidade, nunca sua posse, através de ideias, signos, símbolos, significante/ significado. Portanto, o conhecer não é uma "apreensão real imediata ou mediata ou das coisas do mundo", mas de sua Idea, modelo, paradigma (Platão). 
de sua representação, ele já se encontra comprometido com uma forma de desencobrimento. Trata-se da forma de desencobrimento [desocultamento] da técnica que o desafia a explorar a natureza, tomando-a por objeto de pesquisa até que o objeto desapareça no não-objeto da disponibilidade (HEIDEGGER, 2002, p. 20).

É fundamental que o educador traga, além do conhecimento, história, "à luz da razão" a compreensão e a crítica da técnica e da ciência, bem como a relação ideológica com o mundo econômico, político, social ético e moral. Somente assim o saber produzido se transformará em moeda de grande valor humano e não um simples capital econômico. Mas qual seria a "técnica revolucionária da Filosofia" que mudou a história da humanidade? A descoberta do Lógos e a aplicação dessa "metodologia" a serviço do conhecimento da natureza, física ou humana (naturans naturans e natura naturata $\left.{ }^{13}\right)$.

Filosofia torna-se também uma técnica, do juízo racional, em analisar e compreender a realidade, substituindo ou transformando-se, pela compreensão, a dúvida, as incertezas e as crenças, pela certeza ou "verdades" trabalhadas pela crítica racional. Reflexiva, um repensar permanente (de reflectere, do latim, voltar atrás). Fundamental (que vai às bases, ao fundo, aos fundamentos, "alicerces", da questão, tema ou problema central). Crítico (do grego, kritikós e do latim críticu, quebra: julgamento, juízo rigoroso e grave sobre algo) e analítico (pelo grego análysis, decomposição, divisão ou resolução): trabalho de decompor em partes o conteúdo do objeto de estudo (SOUZA, 2001, p. 30).

Além da Filosofia, da ciência e da arte, a instituição escolar é outra importante contribuição grega à humanidade. A

13 "Natureza sensível", física, fenomênica, phainómenon - "a natureza fazendo o que a natureza faz". "Natureza humana", mundo da criação humana, da subjetividade - "a natureza já criou". Termos adaptados pela Filosofia de Espinosa para designar a objetividade e a subjetividade.

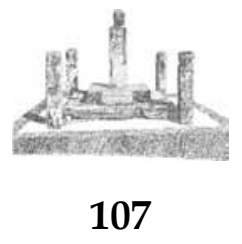

Ano 13 - n. 16 - dezembro 2010 - p. 85-113 
escolarização acontece entre VI e I a.C., do período clássico ao helênico e helenístico à decadência, proposta continuada por Roma. A escolarização grega, inicialmente particular, evoluiu rapidamente para a escola pública, quebrando pouco a pouco consagrados privilégios aristocráticos da educação guerreira homérica, beneficiando o homem livre, depois os estrangeiros, meninas e, por fim, o escravo. Filha da democracia, o direito à educação, aberto a toda gente, cor, ideologia, condição social e econômica, é retomado com intensidade com a burguesia liberal e iluminista como modelo da nova ordem, terminando como bandeira de luta dos trabalhadores por igualdade de direitos.

A escola evoluiu graças às contribuições financeiras de particulares, de cidades ou de soberanos e, aos poucos, se tornará uma escola de Estado. [...] A partir daí, porém, a instrução atingirá não somente as crianças livres (elútheroi paidés), mas também as meninas (párthenoi), os pobres (penétes) e até os escravos (doúloi) [...]. Dessa forma, as escolas foram se tornando gradativamente públicas e, especialmente quando o benfeitor era um soberano (Átalo II, Ptolomeu Filadelfo etc.), se estabilizando. É um processo que o império romano levará adiante: entre os evergetes encontramos os imperadores, como Adriano, que dotou Atenas com um novo ginásio. [...] indubitavelmente significou uma melhoria das condições econômicas e do prestígio social dos mestres, muitos dos quais são lembrados em inscrições públicas ou foram honrados com monumentos (MANACORDA, 2006, p. 67).

A evolução da escola grega, porém, acabou beneficiando, mas não pôs fim à cruel e caótica situação dos professores, extremamente prejudicados econômica, social, política e moralmente como aconteceu na Grécia, porque a situação miserável do mestre em Roma não fora unânime como na Grécia, pois em algumas escolas ou graus, ora o professor era enaltecido ou repudiado. 
Da mais miserável a uma condição de rei: entre estes dois pólos oscilava, na realidade, a condição do mestre nos vários graus de escolas, do litteratur ao grammaticus e ao rhetor, com sensíveis diferenças individuais e locais. [...] também em Roma esta profissão que nem sempre era honrada apresentava, de fato, diferenças muito grandes, inclusive quanto às remunerações, de acordo com o grau da escola e com o prestígio individual dos mestres (MANACORDA, 2006, p. 95).

Finalizando, o compromisso de lutar incondicionalmente em prol da Educação é, em essência e práxis, o objetivo específico do artigo. Por isso defendemos o ensino, em todos os níveis, graus, modalidades e lugares, como urgente prioridade à produção do saber racional sistemático e crítico, ético, social e político-cidadão, e disso não abrimos mão. 


\section{Referências}

ADORNO, T.; HORKHEIMER, M. Dialética do esclarecimento. Rio de Janeiro: Jorge Zahar, 1985.

ARROYO, M.; BUFFA, E.; MOSELLA, P. Educação e cidadania: quem educa o cidadão? São Paulo: Cortez, 2007.

BORNHEIM, G. Os filósofos pré-socráticos. São Paulo: Cultrix, 1972.

BOTURA, G. C. B.; MANZOLI, L. P. A história da Educação Especial na cidade de Ribeirão Preto: um resgate da memória. Disponível em: <http://www.faced.ufu.br/colubhe06/anais/ arquivos/213GeraldaBressianiBotura_e_LuciManzoli.pdf $>$. Acesso em: 28 jul. 2011.

BRANDÃO, C. R. O que é educação. São Paulo: Brasiliense, 2005.

BRASIL. Declaração de Salamanca e linha de ação sobre necessidades educativas especiais. Brasília: CORDE, 1997.

COLL, C.; PALACIOS, J.; MARCHESI, Á. Desenvolvimento psicológico e educação. Necessidades educativas especiais e aprendizagem escolar. Porto alegre: Artes Médicas, 1995.

FOUCAULT, M. A história da loucura na Idade Clássica. Trad. José Teixeira Coelho Netto. São Paulo: Perspectiva, 2005.

GALLO, R. M. A técnica moderna em foco: de princípio civilizador para Karl Marx ao "Gestel" de Martin Heidegger. Socitec e-prints, Florianópolis, v. 1, n. 2, jul-dez. 2005. Disponível em: <http://www.societe.pro.br/e-prints_vol_n.2_a_tecnica_ em foco.pdf $>$ Acesso em: 28 maio 2011. 
GLAT, R. (Org.). Educação Inclusiva: cultura e cotidiano escolar. Rio de Janeiro: 7 Letras, 2007.

HEIDEGGER, M. A questão da técnica. Rio de Janeiro: Jorge Zahar, 2002.

LARROYO, F. História geral da educação. São Paulo: Editora Mestre Jou, 1974.

MANACORDA, M. A. História da educação. São Paulo: Cortez, 2006.

MARCUSE, H. A. Tecnologia, guerra e fascismo. São Paulo: Fundação Editora da UNESP, 1999.

MARX, K. O domínio britânico na Índia - futuros resultados do domínio britânico na Índia. In: MARX; ENGELS. Obras escolhidas. São Paulo: Alfa-Ômega.

MAZZOTTA, M. J. S. Educação especial no Brasil. História e políticas públicas. São Paulo: Cortez, 2005.

NUNES, B. Introdução à filosofia da arte. 3. ed. São Paulo: Ática, 1991.

PAITÁN, C. A. M. 2008: A verdade sobre a gripe suína. Disponível em: <http://idaildo.blogspot.com.br/2009_04_01_archive. html>. Acesso em 01 abr 2009.

SASSAKI, R. K. Construindo uma sociedade para todos. Rio de Janeiro: WVA, 2006.

SENECA, L. A. Sêneca Édipo. Belo Horizonte: UFMG / PROPED, 1982. 
SOUZA, S. S. de. Inclusão de alunos deficientes visuais na universidade: focalizando os professores e os funcionários. $222 \mathrm{f}$. Dissertação (Mestrado em Educação) - Universidade do Estado do Rio de Janeiro, Rio de Janeiro, 2009.

STAINBACK, S.; STAINBACK, W. (Org.). Inclusão. Um guia para educadores. Porto Alegre: Artmed, 1999.

VELLOSO, A. V. O estudo da Filosofia. Belo Horizonte: Edições Júpiter, 1968. 


\section{Importance of critical Education Philosophy: the usefulness of the technique in the process inclusive of people with special needs}

\begin{abstract}
Discusses the technology, education and philosophy. Advocates the importance of philosophy in general education and inclusive education. Discusses the question of "power 'liberator' of technique and industrialization of English capitalism in India", understood as "civilisational principle", a result of "Science/ modern technique", thesis defended industrial postwar era by Marx, and some current implications. Are presented briefly other philosophical ideas-social, economic and ideological (Adorno, Horkheimer, Heidegger, Marcuse) to Marx's model. There are also reflections on the importance of technology in education in General and visual impairment - traditional (Braille writing, for example) and current (digital technologies: computer screen magnified lyrics, specialized software for reading and writing). Are analyzed some pros and cons of technology from the perspective of the objectproblem author on the argumentative text educational inclusion of visually impaired people. Added-if part of the current research of the author on education, which works with the hypothesis that the Greek writing, initiated by Homer, was the most important "contribution revolution" for humanity. The importance of education/pedagogy and the role of the teaching of philosophy in the present day, crucial to the formation of critical consciousness citizen, assumptions, middle and end.
\end{abstract}

Keywords: technique; inclusion; education. 